\title{
Consumo, produção de leite e estresse térmico em vacas da raça Pardo-Suíça alimentadas com castanha de caju
}

\author{
[Dry mater intake, milk yield, and heat stress indicators of dairy cows fed diets with cashew nut] \\ P.G. Pimentel ${ }^{1}$, A.A.A.N. Moura ${ }^{1}$, J.N.M. Neiva ${ }^{2}$, A.A. Araújo ${ }^{1}$, R.F.L. Tair ${ }^{3}$ \\ ${ }^{1}$ Departamento de Zootecnia - UFC \\ Av. Mister Hull, s/n Campus do Pici \\ 60021-970 - Fortaleza, CE \\ ${ }^{2}$ Universidade Federal do Tocantins - Palmas, TO \\ ${ }^{3}$ Aluna de graduação - EV-UFMG - Belo Horizonte, MG
}

\begin{abstract}
RESUMO
Avaliaram-se o consumo de matéria seca, a produção de leite e os indicadores de estresse térmico de vacas Pardo-Suíça alimentadas com castanha de caju no semi-árido do Nordeste do Brasil. Doze animais foram distribuídos em um ensaio de reversão, com quatro tratamentos: $0,8,16$ e $24 \%$ de castanha no concentrado. As vacas receberam cana-de-açúcar à vontade e sete quilos de concentrado por dia. Maior consumo de matéria seca de cana-de-açúcar foi observado no tratamento com concentrado sem castanha $(7,70 \mathrm{kgMS} / \mathrm{dia})$ em relação aos tratamentos com $16 \%$ e $24 \%$ de castanha $(7,35$ e $7,05 \mathrm{kgMS} / \mathrm{dia}$, respectivamente). $\mathrm{O}$ consumo no tratamento com concentrado sem castanha não diferiu do consumo no tratamento com $8 \%$ (7,59kgMS/dia). Não houve efeito dos tratamentos sobre a produção de leite e sobre as variáveis indicativas de estresse térmico $(\mathrm{P}>0,05)$.
\end{abstract}

Palavras-chave: bovino de leite, consumo de matéria seca, produção de leite, estresse térmico

\begin{abstract}
A study was carried out to evaluate dry matter intake, milk yield, and heat stress parameters in Brown Swiss cows fed diets with cashew nut. Animals were raised in the semi-arid region of the Brazilian Northeast. Twelve cows were subjected to a switch back experimental design, with four treatments: 0, 8, 16, and $24 \%$ of cashew nut in the concentrate. Each cow received $7 \mathrm{~kg}$ of concentrate per day and had free access to sugar cane. Dry matter (DM) intake and milk yield were daily taken as well as measurements of rectal and milk temperature; and cardiac and respiratory rates. The highest intake of forage (sugar cane) was obtained when the concentrate had no cashew nut (7.7 kgDM/day). This value was not different when the concentrate contained $8 \%$ of cashew nut $(7.59 \mathrm{~kg} D M /$ day) but greater than dry matter intake of cows receiving diets with $16 \%$ of cashew nut $(7.35 \mathrm{kgDM} /$ day; $P<0.05)$. The diet with $24 \%$ of cashew nut in the concentrate resulted in the lowest consumption of forage (7.05kgDM/day), which was significantly different from all other treatments $(P<0.05)$. Variations in milk yield (from 14.76 to $15.31 \mathrm{~kg} /$ day) were not related to changes in the content of cashew nut in the concentrate $(P>0.05)$. Such low variability in daily milk yield could be associated with the higher energy density of diets containing more cashew nut. Finally, indicators of heat stress were not influenced by changes in the diets, given the air temperatures and environment where all cows were raised.
\end{abstract}

Keywords: dairy cattle, milk yield, dry matter intake, heat stress

Recebido em 13 de junho de 2007

Aceito em 8 de outubro de 2007

E-mail: pgpimentel@hotmail.com 


\section{INTRODUÇÃO}

$\mathrm{Na}$ região Nordeste do Brasil, o manejo alimentar adequado é uma estratégia essencial para o incremento da produtividade dos rebanhos leiteiros, principalmente na época seca, o que torna essencial a utilização de alimentos de adequado valor nutritivo e baixo custo. Assim, são imprescindíveis estudos sobre a viabilidade de alimentos alternativos e a respectiva quantificação das respostas dos animais (Lousada Jr. et al., 2002). Essa região concentra a maior produção de castanha de caju do Brasil (Embrapa, 2001) e o seu subproduto, obtido a partir das amêndoas impróprias ao consumo humano, constitui-se alternativa para alimentação de ruminantes, dado o teor de 27,6\% de proteína bruta e $40,7 \%$ de extrato etéreo na matéria seca (MS) (Pimentel, 2002), além do reduzido custo em relação ao do milho e da soja. A adição de castanha de caju como fonte de lipídeos poderia favorecer o incremento energético da dieta e a relação volumoso:concentrado, reduzir o risco de acidose ruminal e permitir, potencialmente, melhor desempenho das vacas. Contudo, os lipídeos não são utilizados pelos microrganismos do rúmen como fonte de energia, e o seu excesso na dieta (em geral mais de $8 \%$ da matéria seca) pode causar distúrbios metabólicos e redução na ingestão de MS seca e nas concentrações de gordura e proteína no leite (Chilliard, 1993; Wattiaux, 1998).

Há situações em que o fornecimento de lipídeos estaria associado também a aumentos na ingestão de alimentos devido ao baixo incremento calórico durante períodos de estresse térmico, principalmente na região semi-árida onde se observam elevadas temperatura do ar e radiação solar (Oliveira Neto et al., 2001). Animais submetidos à condição de estresse térmico reduzem o consumo de matéria seca e a eficiência de utilização dos nutrientes. Em razão disso, torna-se necessário o fornecimento de dieta com maior densidade de nutrientes de forma que a produção de leite não decline bruscamente quando comparada à condição de termoneutralidade.

A formulação de dietas com baixo incremento calórico para animais termicamente estressados viabilizaria a redução de calor gerado pela fermentação do alimento e metabolismo dos tecidos, diminuindo a carga de calor corporal. O decréscimo na relação forragem:concentrado seria estratégico para o alcance dessa meta, especialmente mediante aumento na concentração de lipídeos na dieta (Beede e Collier, 1986).

Resultados publicados por Chan et al. (1993) mostram que a suplementação de vacas da raça Holandesa com 3,0\% de gordura durante o verão resultou em aumento de $0,6 \mathrm{~kg}$ da produção de leite por dia. No entanto, variações na freqüência respiratória e temperatura retal não foram significativas devido à suplementação com gordura. Em outro experimento (Chan et al., 1997), a conversão de alimentos em leite foi maior em vacas alimentadas com dieta de alta gordura $(7,4 \%$ na $\mathrm{MS})$ que as alimentadas com níveis médios de gordura (4,6\% na MS) por causa do menor consumo de MS. Coppock et al. (1985) detectaram diminuição média de $8,1 \mathrm{mov} / \mathrm{min}$ na freqüência respiratória de vacas alimentadas com $30 \%$ de caroço de algodão na dieta, devido à redução em 10,7\% no consumo de MS e ao menor incremento calórico dos lipídeos. Parece evidente que a literatura ainda apresenta resultados conflitantes sobre a suplementação de vacas com lipídeos em condições de estresse térmico. Portanto, a presente pesquisa teve o objetivo de avaliar os efeitos da inclusão de diferentes níveis de castanha de caju no concentrado sobre os consumos de MS e de nutrientes, sobre produção de leite e sobre indicadores de estresse térmico em vacas da raça Pardo-Suíça criadas no semiárido do Nordeste brasileiro.

\section{MATERIAL E MÉTODOS}

Doze vacas da raça Pardo-Suíça, entre a segunda e a quinta lactação e 50 a 74 dias pós-parto, foram distribuídas em quatro tratamentos (T) em função da adição (\%) de castanha de caju no concentrado: $0 \%$ (T1), $8 \%$ (T2), 16\% (T3) e 24\% (T4). O experimento teve duração de 63 dias, divididos em três períodos de 14 dias de adaptação mais sete dias de coleta de dados cada. Após 14 dias iniciais de adaptação ao sistema de manejo, as vacas foram distribuídas nos tratamentos, considerando-se a ordem de parto e os dias de lactação. Os animais permaneceram confinados durante o dia, em baias sombreadas e, à noite, em áreas livres no estábulo. As dietas foram balanceadas para atender às exigências 
nutricionais das vacas de acordo com o NRC (Nutrient..., 2001). A porção volumosa da dieta consistiu de cana-de-açúcar in natura fornecida à vontade, duas vezes ao dia, às $7 \mathrm{~h}$ e $16 \mathrm{~h}$, permitindo sobras de $10 \%$. O concentrado, $7 \mathrm{~kg}$ de matéria natural/animal/dia (Tab. 1), foi ofertado separadamente da porção volumosa da dieta durante as ordenhas da manhã e da tarde. $\mathrm{O}$ escore corporal (escores de 1 a 5 segundo Wildman et al., 1982) e o peso vivo dos animais foram avaliados a cada período experimental. Desde a fase de adaptação, o consumo voluntário individual de alimento foi determinado diariamente, a partir da diferença entre a quantidade ofertada durante o dia e as sobras, na manhã seguinte. Amostras dos alimentos foram coletadas diariamente e acondicionadas a $-20^{\circ} \mathrm{C}$ para análises dos teores de MS, proteína bruta (PB), fibra em detergente neutro (FDN), fibra em detergente ácido (FDA) e extrato etéreo (Silva, 1990). Como a cana-de-açúcar foi fornecida em ocasião diferente do concentrado, os cálculos dos nutrientes componentes da dieta foram realizados separadamente e, posteriormente, somados para estimativa do total disponível de nutrientes para o animal (Tab. 2).

O conteúdo total de lipídeos nas dietas (cana + concentrado) com $0,8,16$ e $24 \%$ de $\mathrm{CC}$ no concentrado foi, respectivamente, 2,$4 ; 3,7 ; 5,0 \mathrm{e}$ $6,8 \%$, com base na matéria seca, e o teor de MS do concentrado no tratamento $\mathrm{T} 4$ foi mais alto que nos demais tratamentos, o que resultou, embora de forma discreta, em maior teor de proteína bruta na dieta total. A castanha de caju contribuiu com 47,7, 67,3 e 73,5\% do total de extrato etéreo presente no concentrado quando os níveis de inclusão desse ingrediente foram 8,16 e $24 \%$, respectivamente. Os teores de FDN e FDA situaram-se, respectivamente, acima dos níveis mínimos de $25 \%$ e $19 \%$ recomendados pelo NRC (Nutrient..., 1989) para vacas no pico de lactação.

A produção de leite (PL) foi medida duas vezes ao dia, e a eficiência alimentar de cada vaca calculada por meio da relação entre a produção média de leite e a ingestão média de matéria seca (Valadares Filho et al., 2000). As freqüências respiratória (FR) e cardíaca (FC) foram medidas em cada período de coleta durante dois dias consecutivos, às $9 \mathrm{e}$ às 15 horas. Para a freqüência respiratória, usou-se a média de duas contagens consecutivas dos movimentos do flanco por 20 segundos. As temperaturas retal (TR) e do leite (TL) foram determinadas no momento das ordenhas da manhã e da tarde, nos mesmos dias de avaliação das demais variáveis fisiológicas.

Informações sobre as temperaturas máxima, mínima e média na área coberta das instalações foram obtidas às 9, 15 e 19 horas. Obtiveram-se os valores de umidade relativa e temperaturas do bulbo seco e úmido na estação meteorológica da fazenda experimental, localizada próxima à área de execução da pesquisa e, com base nessas variáveis ambientais, calculou-se o índice de temperatura e umidade (ITU; Pires et al., 1998): $\mathrm{ITU}=0,72(\mathrm{TS}+\mathrm{TU})+40,6$, em que: $\mathrm{TS}=$ temperatura do termômetro de bulbo seco $\left({ }^{\circ} \mathrm{C}\right)$ e $\mathrm{TU}=$ temperatura do termômetro de bulbo úmido $\left({ }^{\circ} \mathrm{C}\right)$.

Tabela 1. Composição centesimal dos concentrados utilizados para compor as dietas experimentais, com base na matéria natural, fornecidas a vacas de leite

\begin{tabular}{lcccc}
\hline Ingrediente (\%) & $\mathrm{T} 1$ & $\mathrm{~T} 2$ & $\mathrm{~T} 3$ & $\mathrm{~T} 4$ \\
\hline Farelo de soja & 36,75 & 33,73 & 31,21 & 28,76 \\
Milho & 36,09 & 28,35 & 22,85 & 17,03 \\
Farelo de trigo & 22,39 & 25,00 & 25,00 & 25,00 \\
Castanha de caju & 0,00 & 8,00 & 16,00 & 24,00 \\
Premix mineral/vitamínico & 2,00 & 2,00 & 2,00 & 2,00 \\
Calcário & 1,77 & 1,78 & 1,79 & 1,80 \\
Sal & 0,00 & 0,14 & 0,15 & 0,41 \\
Uréia & 1,00 & 1,00 & 1,00 & 1,00 \\
Total & 100,00 & 100,00 & 100,00 & 100,00 \\
\hline
\end{tabular}

T1: $0 \%$ de castanha; T2: $8 \%$ de castanha; T3: $16 \%$ de castanha; T4: $24 \%$ de castanha. 
Tabela 2. Composição bromatológica (\%) da cana-de-açúcar, dos concentrados contendo diferentes teores de castanha de caju e da dieta fornecida aos animais

\begin{tabular}{|c|c|c|c|c|c|}
\hline \multirow{2}{*}{ Item } & \multirow{2}{*}{ Cana } & \multicolumn{4}{|c|}{ Concentrados $^{1}$} \\
\hline & & $\mathrm{T} 1$ & $\mathrm{~T} 2$ & T3 & $\mathrm{T} 4$ \\
\hline Matéria seca & 34,93 & 89,21 & 89,38 & 89,41 & 89,74 \\
\hline Nutrientes digestíveis totais & $61,00^{1}$ & $74,52^{2}$ & $75,19^{2}$ & $76,36^{2}$ & $77,32^{2}$ \\
\hline Proteína bruta & 1,19 & 25,90 & 26,00 & 26,04 & 26,20 \\
\hline Extrato etéreo & 1,00 & 4,01 & 6,82 & 9,67 & 13,33 \\
\hline Cinzas & 1,02 & 7,70 & 7,15 & 7,43 & 7,77 \\
\hline Fibra em detergente neutro & 52,01 & 11,27 & 11,79 & 12,28 & 12,73 \\
\hline \multirow[t]{2}{*}{ Fibra em detergente ácido } & 31,22 & 7,05 & 7,10 & 7,15 & 7,34 \\
\hline & \multicolumn{5}{|c|}{ Dieta $^{3}$} \\
\hline Nutrientes digestíveis totais & & 67,07 & 67,44 & 68,04 & 68,87 \\
\hline Proteína bruta & & 12,29 & 12,42 & 12,64 & 12,98 \\
\hline Extrato etéreo & & 2,37 & 3,68 & 5,00 & 6,83 \\
\hline Cinzas & & 4,01 & 3,79 & 3,84 & 4,20 \\
\hline Fibra em detergente neutro & & 33,72 & 33,86 & 33,73 & 33,53 \\
\hline Fibra em detergente ácido & & 20,30 & 19,80 & 20,06 & 19,80 \\
\hline
\end{tabular}

T1: $0 \%$ de castanha; T2: $8 \%$ de castanha; T3: $16 \%$ de castanha; T4: $24 \%$ de castanha.

${ }^{1}$ Nutrient... (1989); ${ }^{2}$ Lana (2000).

${ }^{3}$ Cálculos realizados a partir da soma dos teores contidos no volumoso e na porção concentrada.

Os quatro níveis de inclusão de castanha de caju no concentrado foram testados segundo ensaio de reversão que utilizou 12 vacas, uma em cada seqüência, exigida pelo delineamento (Sampaio, 1998). As médias obtidas foram comparadas pelo teste $\mathrm{t}$.

\section{RESULTADOS E DISCUSSÃO}

Os consumos de cana-de-açúcar e total de matéria seca apresentaram variações significativas $(\mathrm{P}<0,05)$ em função dos teores de castanha de caju no concentrado (Tab. 3). Ambos foram mais altos no tratamento sem castanha em relação ao consumo nos tratamentos com 16\% e $24 \%$ de castanha. As dietas com a inclusão de castanha no concentrado resultaram em consumos de MS total equivalentes $(\mathrm{P}>0,05)$, mas o consumo de volumoso só foi semelhante entre os tratamentos com 8 e 16\% de inclusão de castanha. Isso pode ser atribuído ao aumento no teor de matéria seca do concentrado com a inclusão de castanha, ingrediente com teor de MS pouco maior do que os demais, que compensou, em parte, a variação no consumo de cana-de-açúcar.

Tabela 3. Consumo de cana-de-açúcar (CCA) e consumo total (CT) de matéria seca de vacas alimentadas com diferentes teores de castanha de caju (CC) na dieta

\begin{tabular}{lcccc}
\hline Variáveis & T1 & T2 & T3 & T4 \\
\hline CCA $(\mathrm{kg} \mathrm{MS} / \text { dia })^{1}$ & $7,70^{\mathrm{a}}$ & $7,59 \mathrm{ab}$ & $7,35 \mathrm{~b}$ & $7,05 \mathrm{c}$ \\
CT $(\mathrm{kg} \mathrm{MS} / \text { dia })^{1}$ & $14,00 \mathrm{a}$ & $13,70 \mathrm{ab}$ & $13,31 \mathrm{~b}$ & $13,22 \mathrm{~b}$ \\
CCA $(\% \mathrm{PV})^{2}$ & $1,48 \mathrm{a}$ & $1,39 \mathrm{ab}$ & $1,38 \mathrm{ab}$ & $1,37 \mathrm{~b}$ \\
$\mathrm{CT}(\% \mathrm{PV})^{2}$ & 2,73 & 2,60 & 2,68 & 2,80 \\
\hline
\end{tabular}

Médias seguidas de letras diferentes na linha diferem entre si pelo teste $\mathrm{t}(\mathrm{P}<0,05)$.

T1: $0 \%$ de castanha no concentrado; T2: $8 \%$ de castanha no concentrado; T3: $16 \%$ de castanha no concentrado; T4: $24 \%$ de castanha no concentrado.

${ }^{1} \mathrm{CV}=3 \% ;{ }^{2}$ consumo em relação ao peso vivo.

A inclusão de castanha de caju ao concentrado resultou em diminuição de $8,4 \%$ no consumo de cana-de-açúcar (kgMS/dia) e 5,6\% no consumo de MS total no tratamento com $24 \%$ de castanha de caju na porção concentrada da dieta. Embora o presente experimento não forneça subsídios para a explicação da causa exata desses resultados, há a possibilidade de que a alteração no consumo, atribuída à suplementação com lipídeos, se deva a distúrbios na fermentação ruminal e digestibilidade da fibra, além de possíveis efeitos diretos sobre os microrganismos (Jenkins, 1993). 
Outro importante fator que pode estar associado à alteração na ingestão de MS é a sensação de saciedade em razão do alto teor de energia presente no lipídeo. No entanto, a complexidade dos agentes atuantes sobre a sensação de fome e saciedade e sua inter-relação com a regulação do consumo de energia tornam pouco precisa a determinação da quantidade de energia ingerida para desencadear a sensação de saciedade e sua resposta sobre o consumo de alimentos.

Outros aspectos que influenciam o consumo de matéria seca devido à suplementação com lipídeos estão associados à ação de hormônios dos intestinos e ao nível de aceitabilidade das fontes de gordura (Allen, 2000), à quantidade e tipo de ácidos graxos, aos componentes da dieta, à fase da lactação e à quantidade de leite produzido.

A redução no consumo de cana-de-açúcar não influenciou o consumo total de proteína (Tab. 4), pois esse volumoso apresenta baixo teor protéico $(\mathrm{PB}=1,2 \%)$.

A quantidade de extrato etéreo consumida pelas vacas foi diretamente influenciada pelo nível de inclusão de castanha (Tab. 4). Este resultado confirma os já obtidos por Malafaia et al. (1996) com o uso de sebo bovino para vacas leiteiras.

O fato de o milho ter sido o principal ingrediente substituído pela castanha de caju, variação de $52,8 \%$ entre o tratamento-controle e o com $24 \%$ de castanha, seguido pelo farelo de soja, variação de $21,7 \%$, resultou em consumo de extrato etéreo 2,75 vezes maior nos animais suplementados com $24 \%$ de castanha no concentrado em relação àqueles submetidos à dieta-controle. Esse resultado certamente ocorre devido à elevada concentração de extrato etéreo na castanha de caju $(40,7 \%)$ em contraste com o milho (4,2\%; Nutrient..., 2001) e a do farelo de soja (1,6\%; Nutrient..., 2001).

Tabela 4. Consumo total de nutrientes $(\mathrm{kg} / \mathrm{dia})$ de vacas alimentadas com diferentes teores de castanha de caju na dieta

\begin{tabular}{lcccc}
\hline Variável & T1 & T2 & T3 & T4 \\
\hline Nutrientes digestíveis totais $^{1}$ & $9,35 \mathrm{a}$ & $9,34 \mathrm{a}$ & $9,26 \mathrm{a}$ & $9,16 \mathrm{~b}$ \\
Proteína bruta $^{2}$ & 1,71 & 1,72 & 1,72 & 1,73 \\
Extrato etéreo $^{2}$ & $0,33 \mathrm{a}$ & $0,51 \mathrm{~b}$ & $0,68 \mathrm{c}$ & $0,91 \mathrm{~d}$ \\
Fibra em detergente neutro $^{3}$ & $4,70 \mathrm{a}$ & $4,68 \mathrm{a}$ & $4,59 \mathrm{ab}$ & $4,47 \mathrm{~b}$ \\
Fibra em detergente ácido $^{3}$ & $2,83 \mathrm{a}$ & $2,74 \mathrm{~b}$ & $2,73 \mathrm{~b}$ & $2,64 \mathrm{c}$ \\
\hline
\end{tabular}

Médias seguidas de letras diferentes na linha diferem entre si pelo teste $\mathrm{t}(\mathrm{P}<0,05)$.

T1: $0 \%$ de castanha no concentrado; T2: $8 \%$ de castanha no concentrado; T3: $16 \%$ de castanha no concentrado; T4: $24 \%$ de castanha no concentrado.

${ }^{1} \mathrm{CV}=3 \% ;{ }^{2} \mathrm{CV}=1 \% ;{ }^{3} \mathrm{CV}=2 \%$.

A redução $(\mathrm{P}<0,05)$ no consumo de $\mathrm{FDN}$ na dieta com $24 \%$ de castanha no concentrado devese, possivelmente, à alteração observada no consumo de forragem pelos animais submetidos a esse tratamento. O consumo de FDA do tratamento sem castanha e com $24 \%$ de castanha diferiu dos tratamentos com 8 e $16 \%$, que se equivalem $(\mathrm{P}>0,05)$. Portanto, o menor consumo FDA na dieta com maior teor de castanha confirma o menor consumo de MS total obtido neste tratamento.

As médias de produção de leite variaram de 14,8 a $15,3 \mathrm{~kg} /$ dia (Tab. 5) e não foram influenciadas pelos tratamentos $(\mathrm{P}>0,05)$. Esse fato sugere que o consumo de nutrientes foi adequado à manutenção da produção de leite, mesmo com significativo decréscimo na ingestão de MS por parte dos animais submetidos às dietas com maior conteúdo de castanha no concentrado. Vários estudos observaram ausência de efeito da inclusão de lipídeos sobre a produção de leite. Santos et al. (2001) não observaram alteração na produção de vacas leiteiras com a inclusão de até $7 \%$ de lipídeos não protegidos na dieta. Algumas pesquisas mostraram incremento da produção de leite, embora com variações na resposta dos animais devido a diferenças no consumo de MS e nutrientes, nível e tipo de lipídeos fornecidos (Chilliard, 1993). 
Tabela 5. Produção de leite (PL), eficiência da produção de leite (EPL), peso vivo (PV) e escore corporal (EC) de vacas alimentadas com diferentes teores de castanha de caju na dieta

\begin{tabular}{|c|c|c|c|c|}
\hline Variável & $\mathrm{T} 1$ & $\mathrm{~T} 2$ & T3 & $\mathrm{T} 4$ \\
\hline PL $(\mathrm{kg} / \mathrm{dia})^{1}$ & 14,76 & 15,22 & 15,31 & 14,89 \\
\hline EPL ( $\mathrm{kg}$ leite $/ \mathrm{kg} \mathrm{MS})^{2}$ & 1,07 & 1,10 & 1,12 & 1,13 \\
\hline $\mathrm{PV}(\mathrm{kg})^{3}$ & 505,00 & 498,90 & 503,10 & 489,30 \\
\hline EC & 3,30 & 3,30 & 3,30 & 3,20 \\
\hline
\end{tabular}

T1: $0 \%$ de castanha no concentrado; T2: $8 \%$ de castanha no concentrado; T3: $16 \%$ de castanha no concentrado; T4: $24 \%$ de castanha no concentrado.

${ }^{1} \mathrm{CV}=5 \% ;{ }^{2} \mathrm{CV}=6 \% ;{ }^{3} \mathrm{CV}=3 \%$.

O peso vivo e o escore corporal dos animais não foram influenciados pelos tratamentos $(\mathrm{P}>0,05)$. Embora a dieta com maior teor de castanha no concentrado tenha proporcionado redução de $2,3 \%$ no consumo de NDT em relação à dieta sem castanha, essa alteração foi menor que a observada para o consumo de MS total (5,57\%) e de volumoso $(8,4 \%)$, possivelmente devido à maior densidade energética das dietas com níveis elevados de lipídeos. Nesse caso, mesmo o consumo de $9,16 \mathrm{~kg}$ de NDT e $1,73 \mathrm{~kg}$ de PB, observados na dieta com $24 \%$ de castanha no concentrado (Tab. 4), foi o suficiente para manter a produção de leite sem perdas significativas de reservas corporais. De acordo com o NRC (Nutrient..., 1989), vacas com $500 \mathrm{~kg}$ de peso vivo e produção diária de $15 \mathrm{~kg}$ de leite/dia (3,5\% de gordura) devem ingerir o mínimo de $8,28 \mathrm{~kg}$ de NDT e $1,66 \mathrm{~kg}$ de $\mathrm{PB} / \mathrm{dia}$, valores que foram atendidos para todos os níveis de inclusão de castanha de caju.

As temperaturas máxima, mínima e média do ar foram semelhantes durante os três períodos experimentais. À noite, a umidade relativa do ar permaneceu em torno de $78,8 \%$ durante todo o experimento, e com apenas $44,3 \%$ à tarde. $\mathrm{O}$ fato de as menores temperaturas terem sido observadas à noite e as maiores, à tarde, mas nesse último caso associadas à menor umidade, pode ter proporcionado uma situação de maior conforto aos animais, pois a combinação de temperatura e umidade elevada constitui elemento climático estressor (Baccari Jr., 1998). Os limites de ITU variam entre 72-79 para o estresse ameno, 80-89 para estresse moderado e 90-98 para situações de estresse severo (Oliveira Neto et al., 2001). No presente estudo, os valores obtidos com o ITU não variaram acentuadamente durante os três períodos experimentais, com média de 79,7; 82,5 e 76,6 para 9,15 e 21 horas, respectivamente. Durante a manhã e à tarde, os indicadores de conforto térmico oscilaram entre os limites superiores do estresse ameno e inferiores do moderado. Os níveis mais elevados de ITU foram observados às 15 horas (média de $82,5)$, mas o menor valor de ITU no período da noite (21 horas) pode ter permitido dissipação de pelo menos parte da carga térmica adquirida durante o dia.

Os valores TR e TL e as $\mathrm{FR}$ e $\mathrm{FC}$ são apresentados na Tab. 6. TR e TL não apresentaram variações significativas $(\mathrm{P}>0,05)$ em função dos teores de castanha adicionados à dieta, fato que se deve provavelmente à amplitude da variação no consumo diário de MS não ter sido suficientemente elevada. Em média, as TR e TL apresentaram variações de 0,3 a $0,4^{\circ} \mathrm{C}$ e de 0,5 a $0,6^{\circ} \mathrm{C}$ durante a manhã e a tarde, respectivamente. Ao longo do experimento, diferenças de $4^{\circ} \mathrm{C}$ entre a temperatura ambiente da tarde e a da manhã não estiveram associadas a alterações maiores na TR, provavelmente, porque no momento de maior calor $(15 \mathrm{~h}$; média de $33,9^{\circ} \mathrm{C}$ ), a umidade do ar foi $44,3 \%$, o que amenizou a variação no ITU. Em estudo realizado na região semi-árida, Oliveira Neto et al. (2001) também verificaram que, em vacas $3 / 4$ a 7/8 Holandês x Gir, a diferença da TL entre os períodos da manhã e da tarde $(1,1$ a $\left.1,3^{\circ} \mathrm{C}\right)$ foi maior $(\mathrm{P}<0,05)$ que a da TR $(0,1 \mathrm{a}$ $\left.0,2^{\circ} \mathrm{C} ; \mathrm{P}>0,05\right)$. Comparações entre valores de TR e TL gerados em experimentos distintos podem ser pouco precisas, porém, sugere que a TL é mais sensível às variações de temperatura $\mathrm{e}$ umidade do ar que a TR. A razão para esse fato está associada aos mecanismos de termorregulação do organismo e/ou à possibilidade de a glândula mamária apresentar reações especificas ao estresse térmico devido ao intenso processo anabólico (síntese do leite), fluxo sangüíneo anatomia e localização inguinal. 
Tabela 6. Temperatura retal (TR), temperatura do leite (TL), freqüência respiratória (FR) e freqüência cardíaca (FC) durante a manhã (-M) e a tarde (-T) de vacas alimentadas com diferentes teores de castanha de caju na dieta

\begin{tabular}{|c|c|c|c|c|}
\hline Variável & $\mathrm{T} 1$ & $\mathrm{~T} 2$ & $\mathrm{~T} 3$ & $\mathrm{~T} 4$ \\
\hline TR-M ${ }^{1}\left({ }^{\circ} \mathrm{C}\right)$ & 38,70 & 38,60 & 38,70 & 38,60 \\
\hline TR-T $\left({ }^{\circ} \mathrm{C}\right)$ & 39,00 & 39,00 & 39,00 & 39,00 \\
\hline TL-M ${ }^{1}\left({ }^{\circ} \mathrm{C}\right)$ & 37,00 & 37,10 & 37,10 & 37,10 \\
\hline TL-T ${ }^{1}\left({ }^{\circ} \mathrm{C}\right)$ & 37,60 & 37,60 & 37,60 & 37,70 \\
\hline FR-M ${ }^{2}(\mathrm{mov} / \mathrm{min})$ & $43,00 \mathrm{ab}$ & $43,60 \mathrm{ab}$ & $47,00 \mathrm{~b}$ & $41,40 \mathrm{a}$ \\
\hline $\mathrm{FR} \mathrm{T}^{3}(\mathrm{mov} / \mathrm{min})$ & $56,00 \mathrm{ab}$ & $59,80 \mathrm{a}$ & $53,00 \mathrm{~b}$ & $58,30 \mathrm{a}$ \\
\hline $\mathrm{FC}-\mathrm{M}^{3}(\mathrm{pul} / \mathrm{min})$ & 59,00 & 62,00 & 63,40 & 58,40 \\
\hline $\mathrm{FC}-\mathrm{T}^{4}(\mathrm{pul} / \mathrm{min})$ & 65,80 & 66,30 & 66,30 & 63,40 \\
\hline
\end{tabular}

Médias seguidas de letras diferentes nas linhas diferem entre si pelo teste $\mathrm{t}(\mathrm{P}<0,05)$.

T1: $0 \%$ de castanha no concentrado; T2: $8 \%$ de castanha no concentrado; T3: $16 \%$ de castanha no concentrado; T4: $24 \%$ de castanha no concentrado.

${ }^{1} \mathrm{CV}=1 \% ;{ }^{2} \mathrm{CV}=8 \% ;{ }^{3} \mathrm{CV}=7 \% ;{ }^{4} \mathrm{CV}=4 \%$.

Não houve diferença no TR entre os tratamentos sem castanha de caju e os tratamentos com 8 e $16 \%$ de castanha, mas a diferença ocorreu $(\mathrm{P}<0,05)$ entre os dois maiores níveis de inclusão de castanha. A redução na FR apresentada pela dieta com $24 \%$ de castanha no concentrado pode estar relacionada à menor ingestão de matéria seca. No entanto, esse comportamento não ocorreu com a FR da tarde, isto é, o valor obtido para o tratamento com $24 \%$ de castanha foi mais alto que o observado para a inclusão de $16 \%$ de castanha. $\mathrm{O}$ aumento da FR à tarde pode refletir uma tentativa dos animais de, através da respiração, liberar o calor endógeno oriundo da alimentação e modificações ambientais no decorrer do dia. Respostas variadas na FR têm sido encontradas também por outros autores, em função do tipo de suplementação fornecida, nível de estresse térmico e consumo de MS. Por exemplo, Chan et al. (1992) não observaram alterações significativas na FR devido à suplementação com lipídeos em vacas criadas sob temperaturas acima de $40^{\circ} \mathrm{C}$ e alimentadas com feno de alfafa, $8 \%$ de caroço de algodão inteiro e $2,5 \%$ de gordura suplementar. Contudo, Coppock et al. (1985) detectaram diminuição na FR (em média de $8,1 \mathrm{mov} / \mathrm{min}$ ) de vacas alimentadas com 0 a $30 \%$ de caroço de algodão devido ao menor consumo de MS e menor incremento calórico da gordura. Em acordo com os demais parâmetros físiológicos avaliados no presente estudo, a FR apresentou variações independentes dos tratamentos. Os valores obtidos durante a tarde foram mais altos que os da manhã, possivelmente resultantes do aumento da temperatura ambiente e da tentativa do organismo em manter o equilíbrio térmico (Silva, 2000).

\section{CONCLUSÕES}

A utilização de níveis crescentes de castanha de caju no concentrado para vacas em lactação, embora tenha promovido redução no consumo de matéria seca, não alterou a produção de leite. Tal efeito ocorreu, possivelmente, devido à compensação na densidade energética nas dietas com maiores teores de castanha, o que resultou em melhor eficiência da produção sem que reservas corporais tenham sido mobilizadas para esse fim. O ambiente caracterizado por condições de estresse térmico ameno ou moderado deve ter contribuído para esses resultados e para uma reduzida variação no consumo de matéria seca.

\section{REFERÊNCIAS BIBLIOGRÁFICAS}

ALLEN, S.M. Effects of diet on short-term regulation of diet intake by lactating dairy cattle. $J$. Dairy Sci., v.83, p.1598-1624, 2000.

BACCARI Jr., F. Manejo ambiental para produção de leite em climas quentes. In: CONGRESSO BRASILEIRO DE BIOMETEOROLOGIA, 2., 1998, Goiânia. Anais... Goiânia, 1998. p.136-161.

BEEDE, D.K.; COLLIER, R.J. Potential nutritional strategies for intensively managed cattle during heat stress. J. Anim. Sci., v.62, p.543-554, 1986.

CHAN, S.C.; HUBER, J.T.; WU, Z. et al. Effect of fat supplementation and protein source on performance of dairy cows in hot environment 
temperatures. J. Dairy Sci., v.75, Suppl. 1, p.175, 1992. (Abstract).

CHAN, S.C.; HUBER, J.T.; WU, Z. et al. Effect of supplementation of fat and evaporative cooling of dairy cows subjected to hot temperatures. J. Dairy Sci., v.76, Suppl. 1, p.184, 1993. (Abstract).

CHAN, S.C.; HUBER, J.T.; CHEN, K.H. et al. Effect of ruminally inert fat and evaporative cooling on dairy cows in hot environmental temperatures. J. Dairy Sci., v.80, p.1172-1178, 1997.

CHILLIARD, Y. Dietary fat and adipose tissue metabolism in ruminants, pigs and rodents: a review. J. Dairy Sci., v.76, p.3897-3931, 1993.

COPPOCK, C.E.; WEST, J.W.; MOYA, J.R. et al. Effects of amount of whole cottonseed on intake, digestibility, and physiological responses of dairy cows. J. Dairy Sci., v.68, p.2248-2256, 1985.

EMBRAPA apresenta estatísticas e mapas referentes à produção de caju e castanha, 2001. Disponível em:

$<$ http://www.cnpat.embrapa.br/ vitor/>. Acessado em: 04 ago. 2001.

JENKINS, T.C. Symposium: advances in ruminant lipid metabolism. J. Dairy Sci., v.76, p.3851-3863, 1993.

LANA, R.P de. Sistema Viçosa de formulação de rações. Viçosa: Editora UFV, 2000. 60 p.

LOUSADA Jr.; J.E., NEIVA, J.N.M.; PIMENTEL, J.C.M. et al. Consumo e digestibilidade aparente da matéria seca de subprodutos da agroindústria processadora de frutas. In: REUNIÃO ANUAL DA SOCIEDADE BRASILEIRA DE ZOOTECNIA, 39., 2002, Recife. Anais... Recife: SBZ, 2002. (CDROM).

MALAFAIA, P.A.M.; VALADARES FILHO, S.C.; SILVA, J.F.C. et al. Sebo bovino em rações para vacas em lactação. 1. Consumo dos nutrientes, produção e composição do leite. Rev. Bras. Zootec., v.25, p.153-163, 1996.

NUTRIENT requirements of dairy cattle. 6.ed. Washington, DC: National Academic of Sciences, 1989. $158 \mathrm{p}$.

NUTRIENT requirements of dairy cattle. 7.ed. Washington, DC: National Academic of Sciences, 2001. 381p.
OLIVEIRA NETO, J.B.; MOURA, A.A.A.; NEIVA, J.N.M. et al. Indicadores de estresse térmico e utilização da somatotropina bovina (bST) em vacas leiteiras mestiças (Bos taurus x Bos indicus) no semi-árido do Nordeste. Rev. Bras. Zootec., v.30, p.360-367, 2001.

PIMENTEL, P.G. Consumo de matéria seca e nutrientes, produção de leite e indicadores de estresse térmico de vacas pardo-suíço alimentadas com diferentes níveis de castanha de caju no semiárido. 2002. 56 fl. Dissertação (Mestrado em Zootecnia) - Universidade Federal do Ceará, Fortaleza.

PIRES, M.F.A.; CAMPOS, A.T.; FERREIRA, A.M. Importância do conforto, ambiente e instalações no manejo de matrizes leiteiras. In: SIMPÓSIO - O AGRONÉGOCIO DO LEITE NO NORDESTE: ALTERNATIVAS, TECNOLOGIAS E PERSPECTIVAS DE MERCADO, 1998, Natal. Anais... Natal: 1998, p.266-282.

SAMPAIO, I.B.M. Estatística aplicada à experimentação animal. Belo Horizonte: FEPMVZ, 1998. 221p.

SANTOS, F.L.; LANA, R.P.; SILVA, M.T.C. et al. Produção e composição do leite de vacas submetidas a dietas contendo diferentes níveis e formas de suplementação de lipídios. Rev. Bras. Zootec., v.30, p.1376-1380, 2001.

SILVA, D.J. Análise de alimentos: métodos químicos e biológicos. Viçosa: UFV, 1990. 165p.

SILVA, R.G. Introdução à bioclimatologia animal. São Paulo: Nobel, 2000. 286p.

VALADARES FILHO, S.C.; BRODERICK, G.A.; VALADARES, R.F.D. et al. Effect of replacing alfafa silage with high moisture corn on nutrient utilization and milk production. J. Dairy Sci., v.83, p.106-114, 2000.

WATTIAUX, M.A. Guia técnico da pecuária leiteira: nutrição e alimentação. Madison: Instituto Babcock para Pesquisa e Desenvolvimento da Pecuária Leiteira Internacional, 1998. 128p.

WILDMAN, E.E.; JONES, G.M.; WAGNER, P.E. et al. A dairy cow body condition scoring system and its relationship to selection production characteristics. J. Dairy Sci., v.65, p.495-501, 1982. 